$$
\begin{array}{r}
\text { ORDEM E } \\
\text { DESORDEM } \\
\text { EM "FORA } \\
\text { DA ORDEM" } \\
\text { IVA CARLOS } \\
\text { LOPES E } \\
\text { LUIZTATIT }
\end{array}
$$


Resumo Este trabalho pretendeu demonstrar que o sentido formulado com os recursos da cançāo popular provém simultaneamente de suas faces lingüística e melódica. A partir da análise da composição "Fora da Ordem", de Caetano Veloso, verificou-se que tanto as situações de precipitação e atropelo quanto os sinais de um certo arranjo natural dos conteúdos expressos pela letra migram para o setor melódico da canção, onde recebem um reforço dos tratamentos entoativo e musical. Em outros termos, este artigo sugere que, por meio de técnicas particulares de organização, letra e melodia revezam-se para garantir à canção o seu sentido homogêneo. Palavras-chave Caetano Veloso; semiótica; melodia; letra; música.

Abstract This work aimed to demonstrate that the sense formulated with popular song resources comes simultaneously from its linguistic and melodic components. From the analysis of the song "Fora da Ordem", by Caetano Veloso, it was possible to verify that both the situations of precipitation and haste as well as the signs of a certain arrangement of the lyric contents shift to the melodic sector of the song where they are reinforced by intonation and musical treatments. In other words, this article suggests that, thanks to particular arrangement techniques, lyrics and melody alternate themselves in such a way to ensure to the song its homogeneous sense. Keywords Caetano Veloso; semiotics; melody; lyrics; music.

Desde a eclosão do movimento bossa-nova, em 1958, a canção popular brasileira vem atraindo a atenção, não apenas da forte indústria de entretenimento instalada no país, mas também de boa parte da elite cultural que hoje lhe reserva o papel artístico e social anteriormente concedido apenas à literatura e às artes eruditas em geral. Essa condição especial não pode evidentemente ser desvinculada dos grandes artistas que emprestaram ou vêm emprestando o seu talento para a criação de um repertório musical cuja originalidade e qualidade já são reconhecidas em todo o mundo: Tom Jobim, Gilberto Gil, Chico Buarque, Caetano Veloso etc.

Ainda não há modelos de análise compatíveis com o vigor dessa produção musical. Na verdade, um modelo exclusivamente musical, por melhor que fosse, não daria conta das relações entre melodia e letra que nos parecem estar na base do sentido produzido pela canção. Expomos aqui algumas formas de abordagem que poderiam instruir uma prática descritiva mais adequada às particularidades dessa modalidade artística. 
Considerações sobre o plano da expressão da canção Todos os estímulos auditivos, vocais e instrumentais compõem o plano da expressão lato sensu de uma canção popular. Os aspectos visuais, aqueles que promovem a canção a uma dimensão de espetáculo, não serão sequer mencionados porque certamente acrescentariam uma complexidade desproporcional aos objetivos modestos deste trabalho. Mesmo entre os estímulos auditivos, queremos selecionar apenas os que asseguram a identidade de uma canção: a melodia e a letra conduzidas pela voz.

É suficiente, para nossa finalidade, atribuirmos à organização melódica a função de elemento estruturador do plano da expressão e à organização lingüística a incumbência de conformar o plano do conteúdo. Os aspectos sonoros da letra rimas, aliterações, assonâncias -, que pertencem certamente ao plano da expressão, tendem a ocupar, na canção, uma posição secundária diante da exuberância do componente melódico, a menos que o autor lhes dispense algum tratamento especial. Queremos dizer com isso que, embora muitas letras sejam bastante elaboradas do ponto de vista sonoro, o engenho de suas soluções locais não chega a definir essencialmente as diretrizes globais do plano da expressão da obra. Essa tarefa fica a cargo da melodia.

Precisamos lembrar ainda que a melodia da canção brasileira - assim como a de numerosos tipos de canção que grassam pelo planeta - oscila entre a força criadora que emana das entoações de nossa linguagem oral e a forma estruturadora que pertence à linguagem musical propriamente dita. Por serem convocadas normalmente como recurso auxiliar de nossa locução cotidiana, as entoações possuem um caráter pouco autônomo. Suas modulações não formam motivos recorrentes, nāo se ordenam em escalas e nem sequer se estabilizam em alturas definidas. Dispensam leis próprias de organização, visto que o seu modo de atuação se pauta pelas circunstâncias criadas no componente lingüístico: uma ênfase aqui, uma afirmação ali, uma hesitação mais além etc. O único dispositivo prévio que regula essas modulações é o comportamento de seus tonemas (segmentos finais das unidades entoativas) que ora se elevam, indicando prosseguimento do discurso, ora declinam, indicando afirmação, quando não se mantêm na mesma altura, assina-

1 Empregamos aqui as noções de plano da expressão e plano do conteúdo, com as quais L. Hjelmslev reformulou as definições saussurianas de significante e significado.

$88 \neg$ LOPES, Ivã Carlos e TATIT, Luiz. Ordem e desordem em "Fora da ordem" 
lando também uma continuidade, porém menos enfática. À parte esse sistema elementar, muito citado em prosódia, as entoações não se prendem a regras predefinidas - como as musicais, por exemplo - o que as torna desimpedidas para o uso circunstancial da linguagem cotidiana.

Entre as funções desempenhadas pelas leis musicais de ordenação da sonoridade cancional, destaca-se a de controle da instabilidade entoativa. Não fosse por essa função a melodia permaneceria sujeita a todas as veleidades da letra, adequandose instantaneamente a seus acentos, a sua natural proliferação (ou redução) silábica e até a suas oscilações microtonais. Cabe à ordenação musical impor limites à atuação impulsiva das entoações e a sua flexibilidade para se adaptar a qualquer letra, como ocorre no discurso oral. A música contrapõe uma certa métrica que acaba repercutindo na seleção das frases e das palavras, levando em conta não apenas suas isotopias de conteúdo, mas também sua composição silábica e configuração acentual.

Mas isso não significa que as leis musicais sempre prevaleçam sobre o vigor assistemático das modulações entoativas. Há de fato compositores, como Tom Jobim por exemplo, que zelam especialmente pelas leis musicais de ordenação, impondo restrições técnicas aos destemperos entoativos, bem como critérios silábicos e acentuais à escolha lexical. Outros, porém, como Jorge Ben Jor, invertem o pólo hegemônico de construção melódica e sobrepõem a força entoativa à forma musical. Nesse último caso, a melodia se expande, se contrai, perde a simetria, tudo em função de uma letra que se mostra a serviço, quase que exclusivamente, do plano do conteúdo.

Para além dessas configurações estilísticas, os compositores muitas vezes representam a contracena da força entoativa com a forma musical para produzir sentidos no plano da expressão compatíveis com os sentidos engendrados pela letra no plano do conteúdo. É o caso de Caetano Veloso em sua composição "Fora da ordem" Poderíamos iniciar nossos comentários tanto pela melodia como pela letra da composição, mas, para conforto do leitor que nāo esteja habituado a transcrições de melodia, optamos pela apresentação anterior da letra e de suas principais diretrizes de conteúdo. Isso pode nos trazer elementos para o exame posterior de alguns contornos modulados pela voz do cantor. 


\section{A LETRA}

Vapor Barato, um mero serviçal do narcotráfico,

Foi encontrado na ruína de uma escola em construção

Aqui tudo parece que é ainda construção e já é ruína

Tudo é menino e menina no olho da rua

$\mathrm{O}$ asfalto, a ponte, $\mathrm{o}$ viaduto ganindo pra lua

Nada continua

E o cano da pistola que as crianças mordem

Reflete todas as cores da paisagem da cidade que é muito mais bonita e muito mais intensa do que no cartão postal Alguma coisa está fora da ordem

Fora da nova ordem mundial

Escuras coxas duras tuas duas de acrobata mulata, Tua batata da perna moderna, a trupe intrépida em que fluis Te encontro em Sampa de onde mal se vê quem sobe ou desce a rampa

Alguma coisa em nossa transa é quase luz forte demais Parece pôr tudo à prova, parece fogo, parece, parece paz Parece paz Pletora de alegria, um show de Jorge Ben Jor dentro de nós É muito, é grande, é total

Alguma coisa está fora da ordem

Fora da nova ordem mundial

Meu canto esconde-se como um bando de ianomâmis na floresta

Na minha testa caem, vêm colar-se plumas de um velho cocar Estou de pé em cima do monte de imundo lixo baiano Cuspo chicletes do ódio no esgoto exposto do Leblon Mas retribuo a piscadela do garoto de frete do Trianon Eu sei o que é bom 
Eu não espero pelo dia em que todos os homens concordem

Apenas sei de diversas harmonias bonitas possíveis sem juízo final

Alguma coisa está fora da ordem

Fora da nova ordem mundial

Nesse texto, a exemplo de outras letras de Caetano Veloso, vê-se uma sucessão de figuras que compõem um duro quadro urbano do Brasil de dez ou doze anos atrás. São três estrofes pontuadas pelo dístico do refrão: "Alguma coisa está fora da ordem / Fora da nova ordem mundial". De uma estrofe a outra, a perspectiva tornase progressivamente mais embreada, no que diz respeito aos atores: iniciada por dois versos em estilo jornalístico, a primeira estrofe instala uma cena do enunciado em terceira pessoa, embora ancorada no aqui/agora enunciativo, em que se relatam faits divers do cotidiano das grandes cidades brasileiras. Na estrofe seguinte, focaliza-se um par amoroso, o narrador dirigindo-se a um "tu", a "acrobata mulata" que forma com ele um "nós" em situação de intimidade. Embreada já em primeira pessoa, a última estrofe centra a atenção nesse "eu", a observar situações de degradação social em diferentes cidades. O espetáculo da deterioração das condições de vida não impede esse observador, porém, de acenar, em pontos esparsos, com algum gozo, seja de ordem sensual (a "acrobata mulata", suas coxas, sua batata da perna; o garoto de frete do Trianon), seja de ordem artística (o "show de Jorge Ben Jor dentro de nós").

É fácil reconhecer um certo número de "taras sociais" que, à época, chamavam a atenção da nação para um processo de degradação especialmente, mas não exclusivarnente, das cidades. Caetano inclui na letra mençōes a incidentes do cotidiano tais como, no âmbito urbano, o episódio de um policial que, durante uma blitz, obriga um menino de rua a manter o cano de seu revólver dentro da boca, ou, na floresta, os índios ianomâmi do extremo noroeste da Amazônia constrangidos a recuar perante a invasão de suas terras por garimpeiros migrados de outras regiões do país.

A rapidez dos processos de transformação das grandes cidades no Brasil, em comparação com o que sucede em outros países - há alusões às cidades de São Paulo, Brasília, Salvador, Rio de Janeiro - está figurativizada pela construção e pela ruína, par que podemos tomar como uma chave aspectual para a leitura dessa 
canção e, ao mesmo tempo, como indicador de uma instância (aspectual) mais profunda cujas propriedades categoriais permitem instituir as operações semisimbólicas que tornam compativeis entre si o plano da expressão e o plano do conteúdo:

Aqui tudo parece que é ainda construção e já é ruína

São dois aspectos encavalados: o pré-incoativo (construção) e o pós-terminativo (ruína), que se imbricam (como ocorrerá a imbricação métrica dos versos finais de estrofe) porque falta a duratividade que poderia mantê-los separados:

Nada continua

Acontece que a imbricação entre "construção" e "ruína" vem acompanhada pela associação do primeiro com o ainda-parecer e do segundo com o já-ser. Essa situação de interpenetração entre o ainda e o já responde, aqui, tanto pelo efeito específico de ilusão (não ser + parecer), quanto pelo colapso da duração acima assinalado, e ainda pela geração dos efeitos passionais da surpresa, se recordarmos aquela conhecida passagem de Valéry, aqui livremente traduzida:

Noção dos retardamentos.

O que (já) é, não é (ainda) - eis a Surpresa.

O que não é (ainda), (já) é - eis a espera. ${ }^{2}$

Ora, se reconstituirmos, com os termos de Valéry, as etapas aspectuais pressupostas pelo verso de Caetano, atribuindo-lhes uma disposição linear possível e, digamos, desejável, nesse contexto de sucessão inexorável, mas gradativa, da construção à ruína, teremos talvez algo próximo do seguinte esquema:

2 "Notion des retards. Ce qui est (déjà) n'est pas (encore) — voici la Surprise. Ce qui n'est pas (encore) est (déjà) voilà l'attente." valéry, Paul. Cahiers. 3 a ed. Paris: Gailimard/La Pléiade, 1973 t. I, p. 1290.

$92 \neg$ LOPES, Ivã Carlos e TATIT, Luiz. Ordem e desordem em "Fora da ordem" 


\begin{tabular}{|c|c|c|c|c|c|c|c|}
\hline \multicolumn{4}{|c|}{ CONSTRUÇĀO } & & & & \\
\hline \multirow[t]{3}{*}{$\begin{array}{c}\text { Ainda } \\
\text { não parece } \\
\text { ser }\end{array}$} & $\begin{array}{c}\text { Já } \\
\text { parece } \\
\text { ser }\end{array}$ & $\begin{array}{l}\text { Ainda } \\
\text { parece } \\
\text { ser }\end{array}$ & $\begin{array}{l}\text { Já não } \\
\text { parece } \\
\text { mais ser }\end{array}$ & & & & \\
\hline & & & & $\begin{array}{l}\text { Ainda } \\
\text { não é }\end{array}$ & Já é & Ainda é & $\begin{array}{l}\text { Já nāo } \\
\text { é mais }\end{array}$ \\
\hline & & & & & & & \\
\hline
\end{tabular}

Ou seja, esperamos que em princípio ambas as figuras, a construção e a ruína, apresentem ciclos aspectuais não-coincidentes em nenhuma de suas etapas (demarcações e durações) internas e, até mesmo, que haja um intervalo entre a finalização do primeiro ciclo [já não parece mais ser - construção] e o início do segundo [já é - ruína]. A etapa [ainda não é - ruína] cumpre justamente esse papel de representar a duração intermediária entre um ciclo e outro.

Entretanto, se nos deixarmos guiar pelas previsibilidades já contidas nesse esquema aspectual e pelo encavalamento de etapas proposto no verso de Caetano Veloso, veremos que o modelo pode sofrer diferentes graus de aceleração até atingir a desconfortável precipitação formulada pelo compositor. Primeiramente, está prevista uma notória diminuição do intervalo entre os ciclos:

\begin{tabular}{|c|c|c|c|c|c|c|}
\hline \multicolumn{4}{|c|}{ CONSTRUÇÃO } & & & \\
\hline \multirow[t]{3}{*}{$\begin{array}{c}\text { Ainda } \\
\text { nāo parece } \\
\text { ser }\end{array}$} & $\begin{array}{c}\text { Já } \\
\text { parece } \\
\text { ser }\end{array}$ & $\begin{array}{l}\text { Ainda } \\
\text { parece } \\
\text { ser }\end{array}$ & $\begin{array}{c}\text { Já não } \\
\text { parece } \\
\text { mais ser }\end{array}$ & & & \\
\hline & & & $\begin{array}{l}\text { Ainda } \\
\text { nảo é }\end{array}$ & Já é & Ainda é & $\begin{array}{l}\text { Já não } \\
\text { é mais }\end{array}$ \\
\hline & & & \multicolumn{4}{|c|}{ RUINA } \\
\hline
\end{tabular}

Assim que o primeiro ciclo se extingue [já não parece mais ser - construção], inicia-se o segundo [já é - ruína]. Mas o intervalo pode desaparecer completamente se a terminatividade da construção coincidir exatamente com a incoatividade da ruína: [já não parece mais ser — construção] = [já é — ruína]. 


\begin{tabular}{|c|c|c|c|c|}
\hline \multicolumn{5}{|c|}{ CONSTRUÇÃo } \\
\hline $\begin{array}{c}\text { Ainda } \\
\text { não parece } \\
\text { ser }\end{array}$ & $\begin{array}{c}\text { Já } \\
\text { parece } \\
\text { ser }\end{array}$ & $\begin{array}{c}\text { Ainda } \\
\text { parece } \\
\text { ser }\end{array}$ & $\begin{array}{c}\text { Já não } \\
\text { parece } \\
\text { mais ser }\end{array}$ & \multicolumn{2}{|c|}{} \\
\hline & $\begin{array}{c}\text { Ainda } \\
\text { não é }\end{array}$ & Já é & Ainda é & $\begin{array}{c}\text { Já não } \\
\text { é mais }\end{array}$ \\
\cline { 2 - 4 } & \multicolumn{4}{|c|}{ RUÍNA } \\
\cline { 2 - 4 }
\end{tabular}

O que Caetano Veloso denuncia, finalmente, é a precipitação dramática do ciclo de ruína em pleno curso de um processo que parecia ainda ser o de construção:

\begin{tabular}{|c|c|c|c|c|}
\hline \multicolumn{4}{|c|}{ CONSTRUÇĀO } & \\
\hline \multirow[t]{3}{*}{$\begin{array}{c}\text { Ainda } \\
\text { nāo parece } \\
\text { ser }\end{array}$} & $\begin{array}{c}\text { Já } \\
\text { parece } \\
\text { ser }\end{array}$ & $\begin{array}{c}\text { Ainda } \\
\text { parece } \\
\text { ser }\end{array}$ & $\begin{array}{l}\text { Já não } \\
\text { parece } \\
\text { mais ser }\end{array}$ & \\
\hline & $\begin{array}{l}\text { Ainda } \\
\text { não é }\end{array}$ & W. Jáé & Ainda é & $\begin{array}{l}\text { Já não } \\
\text { é mais }\end{array}$ \\
\hline & \multicolumn{4}{|c|}{ RUINA } \\
\hline
\end{tabular}

A aceleração levada ao paroxismo produz essa desarmonia aspectual cujos efeitos serão percebidos, não apenas nas imbricações narrativas e figurativas da letra, mas também na estruturação melódico-entoativa, conforme veremos adiante.

Essa falta apontada de duratividade acarreta, portanto, a reivindicação de uma certa desaceleração, valorizada positivamente em meio a um quadro de aceleração caótica. Dessa aceleração descontrolada, dessa precipitação, resulta a contração e, no limite, a pulverizaçāo daquilo que Fontanille e Zilberberg denominam extensidade ${ }^{3}$

3 A semiótica tensiva praticada na atualidade preconiza que, subjacentes ao sentido formulado nos textos, interagem forças da intensidade e formas da extensidade. Às primeiras são atribuidas as variações de andamento (celeridade e morosidade) ou de acento (tônico e átono) enquanto às últimas são reservadas as variações temporais (brevidade e alongamento) ou espaciais (oclusão e abertura). A aceleração do andamento, por exemplo, pode causar uma contração temporal - uma precipitação dos acontecimentos - assim como sua desaceleração pode produzir um dilatamento na temporalidade, desdobrando-a em diversas etapas. Cf. fontanil.le, Jacques e ZILberberG, Claude. Tensão \& significação. São Paulo: Discurso Editorial/Humanitas, 2001. 
(duração e espaço). É o que se verifica na primeira estrofe. Pulverização da duração ("Nada continua"), bem como encolhimento do espaço: todas as cores da paisagem da cidade são comprimidas no cano da pistola mordida pelas crianças.

Não é, contudo, a narratividade que salta aos olhos nessa canção, e sim a força das figuras arroladas, que pintam um panorama predominantemente sombrio da nação naquele momento; mesmo nos trechos com maior presença de transformações narrativas, como a primeira estrofe, essas transformações encontram-se a serviço da caracterização de um "estado de coisas", e não valem nunca por si mesmas. Nossa hipótese é simplesmente que a narratividade fica obliterada pela falta de duratividade ("Nada continua") a que acabamos de fazer alusão: tudo está atropelado demais para que seja possível reconhecer uma narratividade dotada de fases distintas, umas após outras. Em decorrência disso, a disjuntividade predomina - como experimentar a conjunção, quando não há duração controlável para que o sujeito possa senti-la? -, e é somente através de lampejos circunscritos que se vislumbra, aqui e ali, a possibilidade de conquistar estados conjuntivos. O sentimento de "disparada" tem sido uma constante nas descrições do Brasil quando observado por olhos estrangeiros, e em particular europeus, desde há muito. Está ilustrado exemplarmente pelo psicanalista italiano Contardo Calligaris, que, tendo vivido algum tempo no país, publicou, no mesmo ano do lançamento do CD Circuladô, um livro intitulado Hello Brasill!, com impressões suas acerca da nossa vida social. Nele, o autor evoca a "notável aceleração da vida brasileira" e a "pressa de viver" que nos caracterizaria como povo, chegando a falar na "forma de vida" local em termos de "uma corrida para o gozo e a morte" (p. 96). ${ }^{5}$ Esse frenesi de uma vida excessiva na ordem da intensidade e insuficiente na ordem da extensidade é reportado por Caetano Veloso no caso que nos interessa, mas com a condição de percebermos que, no compositor baiano, o quadro se complexifica, tornando impossível ou vã qualquer rotulação global que tentasse abarcar com uma única solução de conjunto aquilo que ele está observando.

"Disparada" deve ser entendida na acepção etimológica de "des-parada", algo como uma desestagnação, mas também no seu sentido usual de "correria desordenada". Não podemos deixar de levar em conta a célebre canção de Geraldo Vandré, cujo título talvez tenha sintetizado esse ímpeto brasileiro tal como se manifestava nos anos 60.

5 calligaris, Contardo. Hello Brasil! 4a ed. São Paulo: Escuta, 1996. 
Diversos traços singularizam a segunda estrofe, dando-lhe um caráter de "ilhota eufórica" dentro de um panorama globalmente disfórico. Sob o ponto de vista da aspectualidade profunda, aparece aqui uma fluidez que contrasta com os tropeços verificados em outras partes: “... a trupe intrépida em que fluis”. A conjunção narrativa ("Te encontro em Sampa...") responde uma figuratividade de exaltação, com a beleza física da "acrobata mulata" - a alusão à "trupe intrépida" à qual pertence essa personagem remete a um grupo circense-teatral carioca explicitamente homenageado pelo compositor, a Intrépida Trupe - e o show “internalizado" de Jorge Ben Jor, formando uma configuração temática de prazer e alegria também marcados pelo excesso ("Alguma coisa em nossa transa é quase luz, forte demais [...] Pletora de alegria"; "É muito, é grande, é total"). Soma-se a isso o fato de não aparecer aí, ao menos não de maneira tão evidente, a concessividade manifesta das estrofes 1 e 3. Concessão, na estrofe 1: "Aqui tudo parece que é ainda construção $e$ já é ruína", onde esse "e" traduz-se por um "... e, no entanto, ..." - ou seja, embora tudo pareça construção, é ruína; embora haja o horror da cena do policial enfiando o cano da pistola na boca das crianças, esse cano reflete belas cores da paisagem da cidade. $\mathrm{Na}$ estrofe 3: "Cuspo chicletes do ódio no esgoto exposto do Leblon / Mas retribuo a piscadela do garoto de frete do Trianon" - ou seja, embora se esteja num ambiente deteriorado e sujo, há a possibilidade de um gozo "de frete". Em suma, a segunda estrofe destaca-se do conjunto, fazendo contraponto, sob vários aspectos, ao primeiro e ao terceiro trechos da letra. Existe uma senha para essa singularidade da segunda estrofe: a palavra ordem do título aparece, em cada estrofe, incluída numa palavra mais extensa. Na primeira, é "mordem" e, na terceira, "concordem", ambas na posição final do penúltimo verso, preparando a rima para o primeiro verso do refrão, do mesmo modo como o último verso da estrofe fornece a rima para o segundo do refrão. Já na estrofe intermediária, a senha vem anagramatizada em seu segundo verso, dentro da palavra "moderna", não em posição final, mas pelo meio do verso, e sobretudo não na ordem normal mas, desta vez, fora da ordem. Nem por isso podemos recortar a canção em dois blocos, contrapondo o conjunto constituído pelas estrofes 1 e 3 à estrofe 2: se, do ponto de vista das emoções, a primeira estrofe é marcadamente disfórica e a segunda reúne figuras da euforia, a terceira já é mais ambivalente a esse respeito, como se mesclasse ambos os juízos em um agridoce que não permite definir um "juízo final" acerca do que está retratando. 
Qualquer que seja o plano de análise em que nos situemos, portanto, não podemos nos contentar com caracterizações "em bloco", inteiriças, para a interpretação de "Fora da ordem". Aquela concessividade que identificamos já na primeira estrofe estende-se por toda parte e, numa canção que evoca uma "disparada" que impede a experiência, pelo sujeito, de um estado juntivo, convida-nos a desacelerar o olhar descritivo, para não perdermos de vista a complexidade dos juízos aí presentes. Se a primeira estrofe é dominada por figuras de miséria e horror, ela não deixa de assinalar a "beleza" e "intensidade" da paisagem urbana tragicamente refletida no cano do revólver mencionado acima. Analogamente, na terceira estrofe prevalecem as imagens de despossessão (ianomâmi) e de poluição urbana, e no entanto vem a promessa de gozo sexual com o "garoto de frete do Trianon". Embora mais homogênea que as demais, a estrofe intermediária, basicamente eufórica, não deixa de incluir aquele "Sampa, de onde mal se vê quem sobe ou desce a rampa", onde se marca, no mínimo, uma dificuldade de conjunção cognitiva, estando o observador mal capacitado, em São Paulo, para acompanhar o que se passa no cerne do poder político federal (alusão ao ritual de posse, em Brasília, dos presidentes da República).

As versões do refrão em outras línguas, ao final da gravação, conferem expressão mais clara a algo que já se adivinhava. Versão inglesa: "It seems that something has gone out of order / Out of new world order”. Aquém da evidente remissão à situação de hegemonia norte-americana sobre o conjunto do planeta (chamada pelos governantes americanos de "New World Order" e que equivale mais ou menos a dizer... Brave New World), crescentemente afirmada desde o desmoronamento do bloco soviético e a Guerra do Golfo, no limiar dos anos 1990, é preciso atentar para o valor tensivo da expressão out of order, usada para qualificar um mecanismo ou uma máquina em pane: parada de um dispositivo que já não funciona direito, de um mecanismo bloqueado. A canção escancara feiúra e violência dentro de um quadro pintado em tons de rosa pelo "pensamento único" imposto de cima para baixo. Isso posto, e tendo-se inserido dentro da cena ao lado dos atores do enunciado, na embreagem actorial da terceira estrofe, o "eu" volta a valorizar a pluralidade de vozes/opiniões ("Eu não espero pelo dia em que todos os homens concordem") e acena com as "diversas harmonias bonitas possíveis sem juízo final", possibilidades de conjunção não num virtual momento de transcendência última ("juízo final”), mas nesse mesmo mundo perturbado em que ele encena sua própria presença. 
$1^{\mathrm{a}}$ seqüência

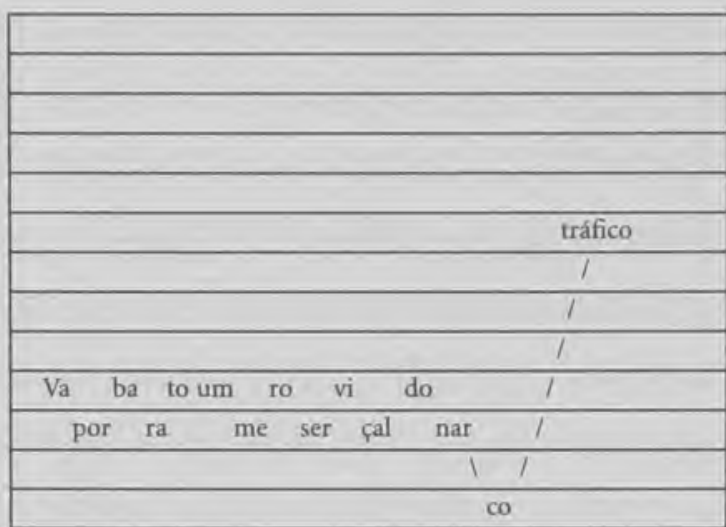

$2^{\mathrm{a}}$ seqüência

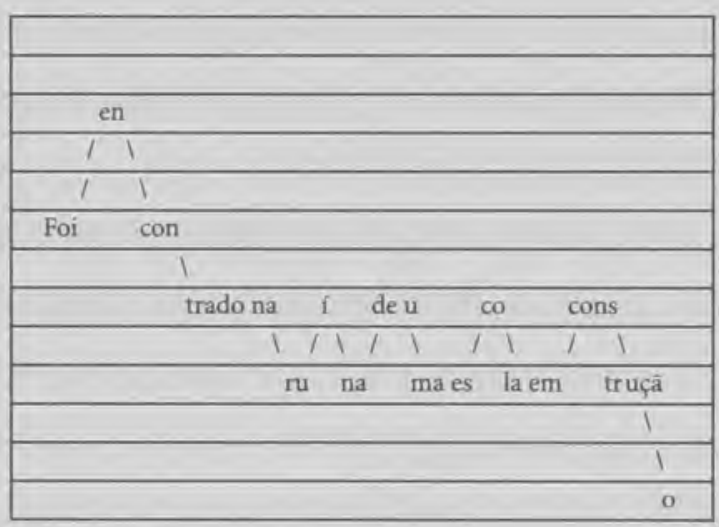

\section{$3^{\text {a }}$ seqüência}

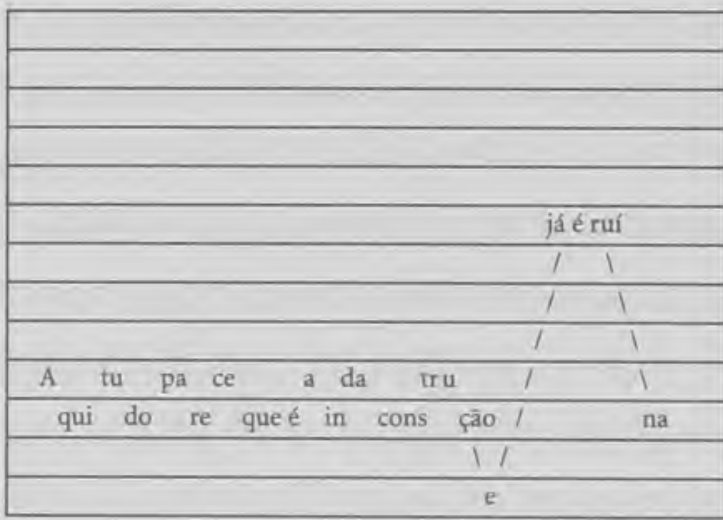




\section{$4^{\mathrm{a}}$ seqüência}

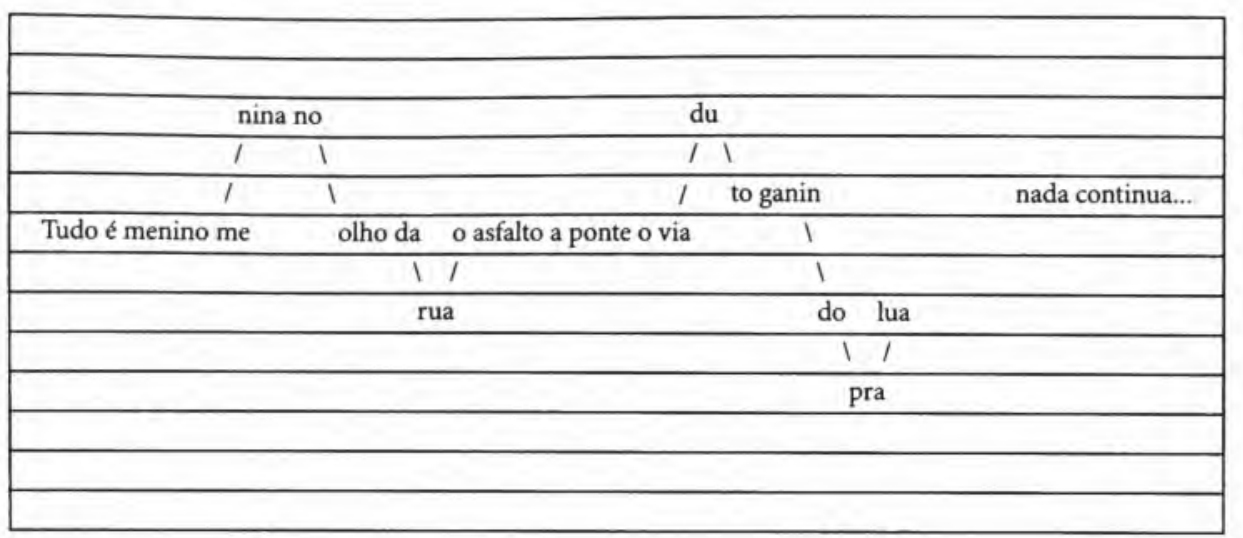

\section{$5^{\text {a }}$ seqüência}

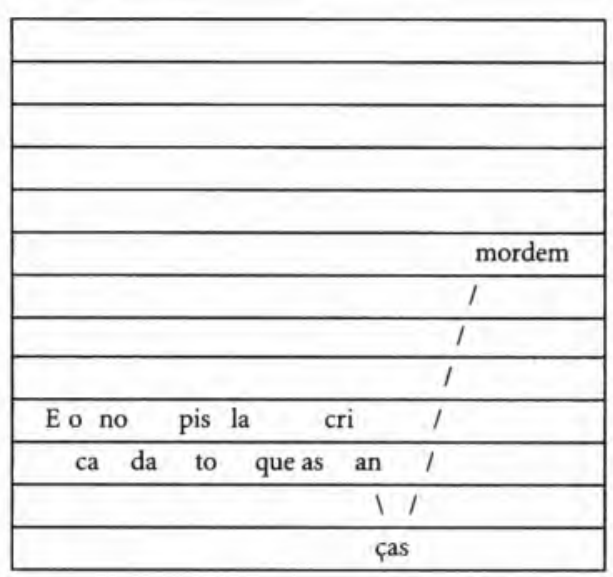

\section{$6^{\text {a }}$ seqüência}

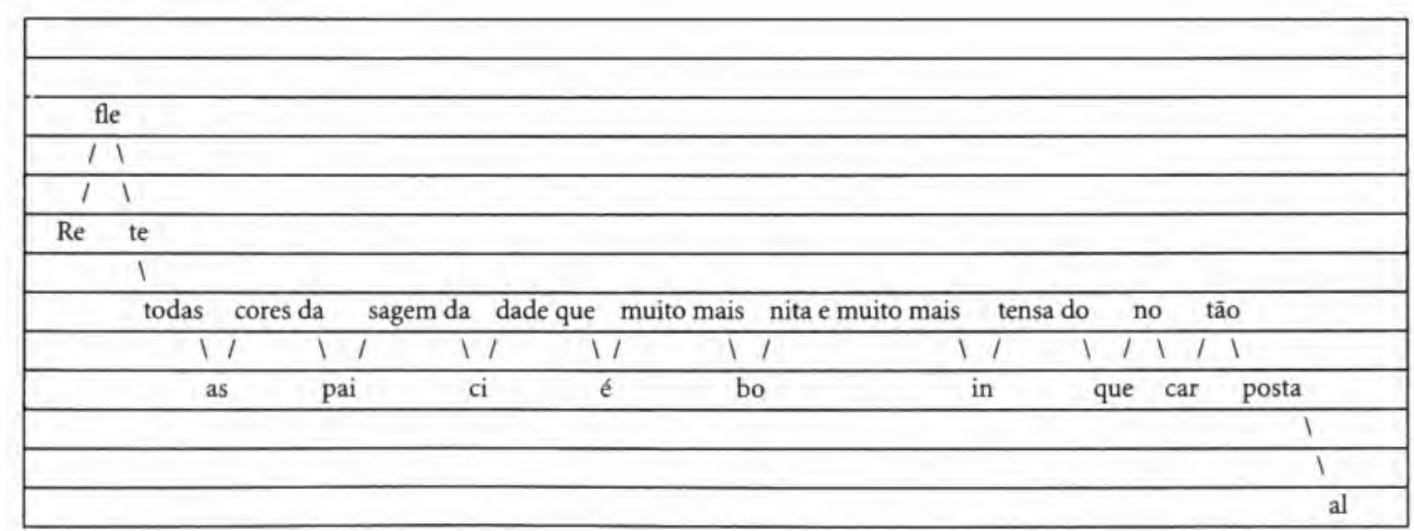

Teresa revista de Literatura Brasileira [4 |5]; São Paulo, p. 86-107, 2004. $\vdash 99$ 
$7^{\mathrm{a}}$ seqüência

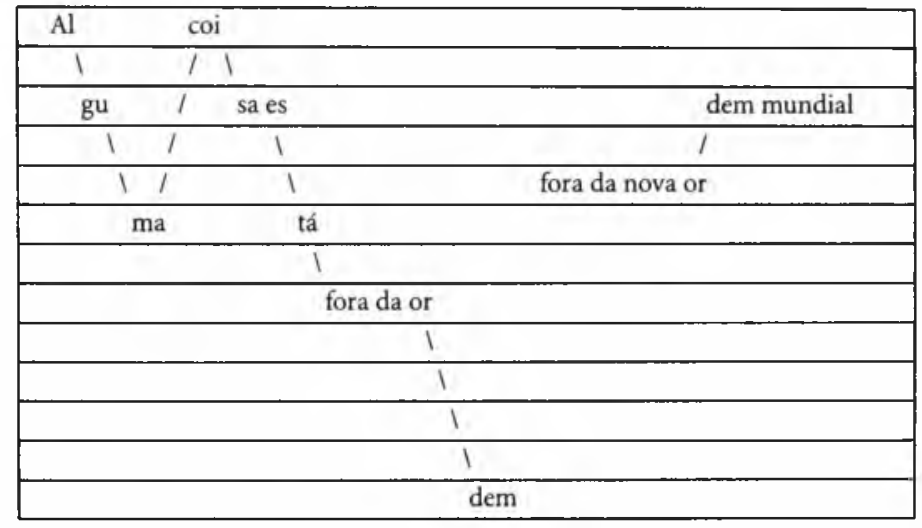

A transferência do andamento acelerado e da imbricação dos ciclos aspectuais para o plano da expressão ou, mais precisamente, para o componente melódico da canção manifesta-se em procedimentos necessariamente lineares e, digamos, analógicos, cuja identificação pode ser realizada a partir da transcrição ${ }^{6}$ parcial feita acima e do confronto de alguns de seus segmentos principais.

Tomemos como exemplo as duas frases melódicas iniciais, que reproduzem de algum modo o padrão entoativo das finalizações (tonemas) ascendentes e descendentes, típico da linguagem cotidiana:

$1^{\text {a }}$ seqüência

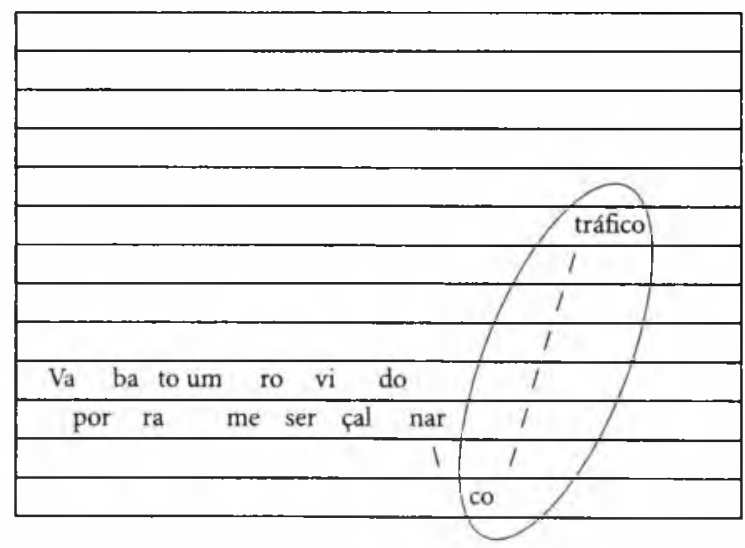

6 O uso de diagramas, como os que vêm a seguir, para transcrever simultaneamente melodia e letra parece-nos mais adequado a este gênero de demonstração. Cada espaço corresponde a um semitom e seu conjunto, ao campo integral de tessitura utilizado pela canção.

$100 \neg$ LOPES, Ivã Carlos e TATIT, Luiz. Ordem e desordem em "Fora da ordem" 
$2^{\mathrm{a}}$ seqüência

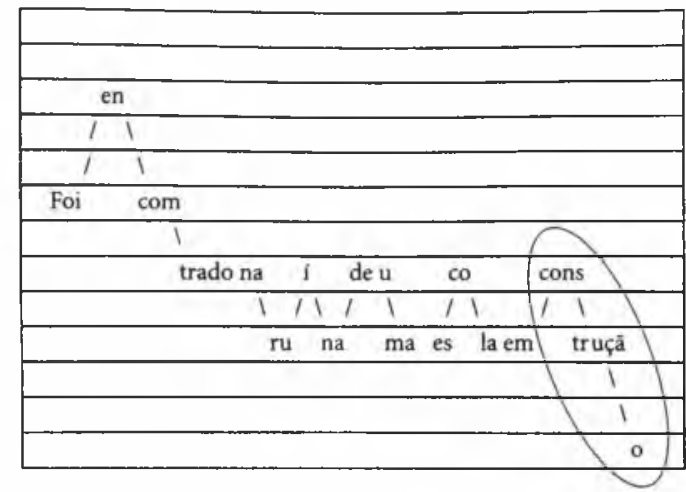

O tonema da primeira seqüência tem a função de preparar (ou convocar) a asserção que se traduz pelo descenso do tonema da segunda. Trata-se de uma oposição muito freqüente nas canções, que contribui para a "ilusão" enunciativa que todas provocam. O corpo das mesmas frases entoativas, por outro lado, deixa transparecer a predominância de um movimento oscilatório em torno de pequenos intervalos, de semitom (na primeira seqüência) ou de um tom (na segunda), que terá função importante na incorporação das categorias aspectuais e cinemáticas ${ }^{7}$ já comentadas. Isso se deve à natureza flexível dos motivos melódicos formados a partir desse gênero de movimento, que cedem facilmente aos impulsos de multiplicação ou redução silábica. Comparemos, por exemplo, a primeira e a terceira seqüências que, a princípio - pela forma musical que se fixa ao longo da canção -, deveriam apresentar o mesmo desenvolvimento melódico:

\section{$1^{\mathrm{a}}$ seqüência}

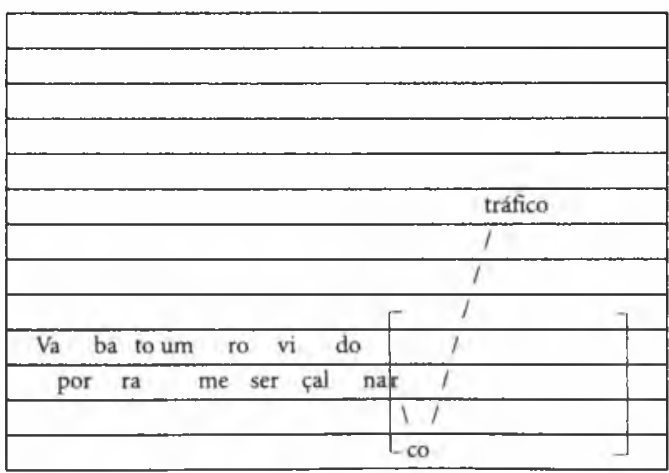

7 As categorias cinemáticas são aquelas que articulam o andamento em aceleração e desaceleração. Cf. ZILBERBERG, Claude. Ensayos sobre semiótica tensiva. Lima: Universidad de Lima/ FCE, 2000, p. 35-6. 
$3^{\text {a }}$ seqüência

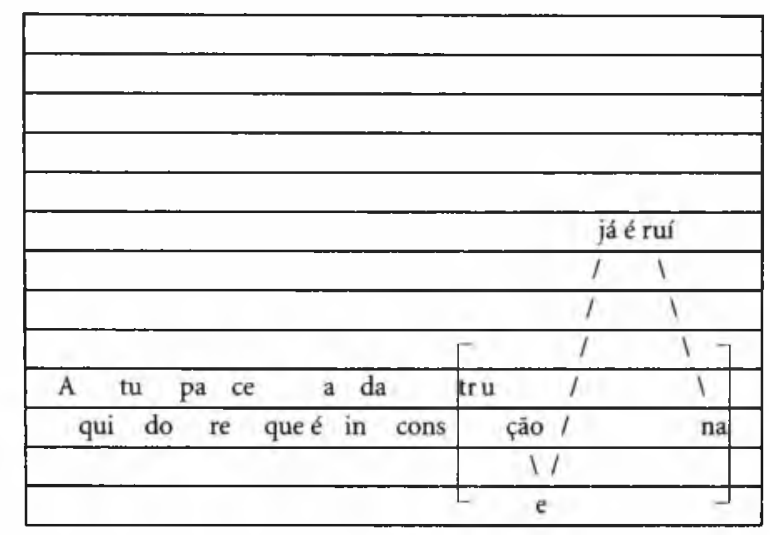

De fato, a forma geral dos contornos se mantém, mas isso não impede que ocorra um aumento do conjunto silábico (delimitado por colchetes) correspondente ao mesmo segmento melódico nas duas seqüências. Não impede também que haja pequenas alterações silábicas e entoativas nos segmentos exteriores aos colchetes, embora não as consideremos neste trabalho.

Se compararmos agora a asserção da segunda seqüência com a asserção da sexta (referente aos oitavo e nono versos), ambas, novamente, norteadas pela mesma forma musical, encontraremos uma solução totalmente imprevisível no âmbito das leis melódicas formuladas até este trecho:

$2^{\mathrm{a}}$ seqüência

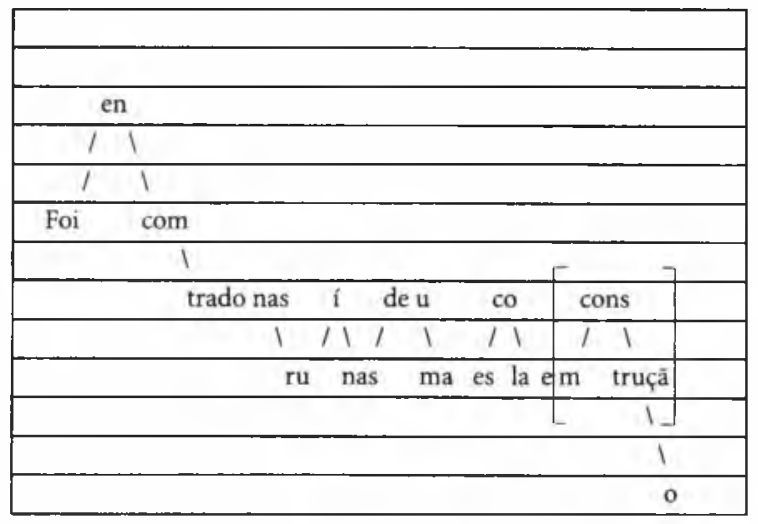


$6^{a}$ seqüência

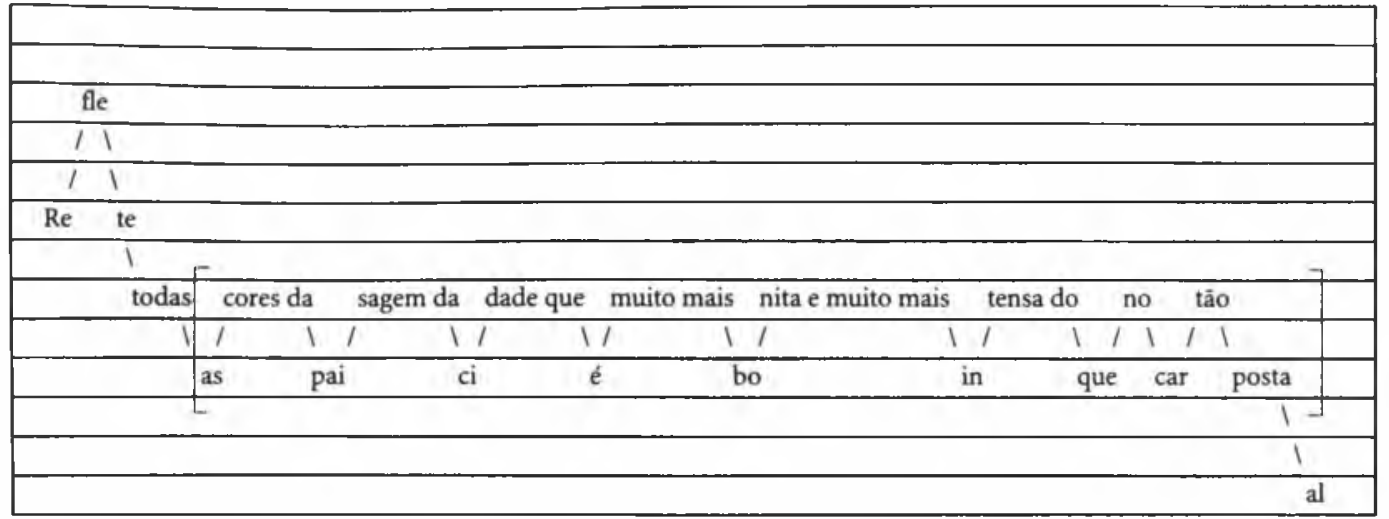

Ainda que se preserve o perfil melódico, a proliferação silábica da sexta seqüência é tão farta que acaba ultrapassando os compassos previstos pelo arranjo instrumental (a pulsação rítmica cessa antes que termine a frase do canto). Esse procedimento é repetido, com outra letra, na apresentação da terceira estrofe.

Temos aqui, em primeiro lugar, um caso típico de supremacia da força entoativa sobre a forma musical. O ímpeto de "dizer" não se sujeita aos limites impostos pela métrica predefinida. Embora respeitem o perfil melódico, as notas musicais se desdobram em quantas sílabas forem necessárias para expressar o conteúdo da letra. Em segundo lugar, para que os elementos da sexta seqüência ocupem, na medida do possível, o espaço circunscrito na segunda, desenvolve-se um processo de aceleração de todo o segmento que provoca um efeito de congestionamento silábico e lexical. Em outras palavras, não há duração suficiente para o encadeamento ordenado das pequenas células melódicas que oscilam em intervalos de segunda. Esse atropelo das notas (e das sílabas) na melodia reproduz, no plano da expressão, a mesma precipitação e a mesma pulverização da extensidade mencionadas na análise da letra. São maneiras, melódicas e lingüísticas, de traduzir a imbricação aspectual profunda.

Por fim, essa preponderância do vigor entoativo sobre a forma melódica assinala no plano da expressão a mesma tendência à embreagem actorial já descrita no plano do conteúdo. Alterar modulações prosódicas em proveito das circunstâncias retratadas no componente lingüístico é um fenômeno próprio da situação de enunciação. Soa como se, por um momento, o "eu" substituísse o canto, com suas leis musicais, pela fala pura e simples, deixando-se conduzir pelas determinações 
do aqui e agora. Nesse sentido, a inflexão entoativa funciona como um dêitico a mais, em reforço às marcas enunciativas.

Por outro lado, esse modo de estabelecer relação entre melodia e letra, com ataques silábicos excedendo nossa expectativa métrica, possui uma contrapartida que permite a substituição temporária da supremacia entoativa (aquela que permite o ímpeto da multiplicação silábica) pelo equilíbrio rítmico musical, sob a ordenação regular dos tonemas: ascendência na quinta seqüência e descendência na sexta:

$5^{\text {a }}$ seqüência da $2^{a}$ estrofe

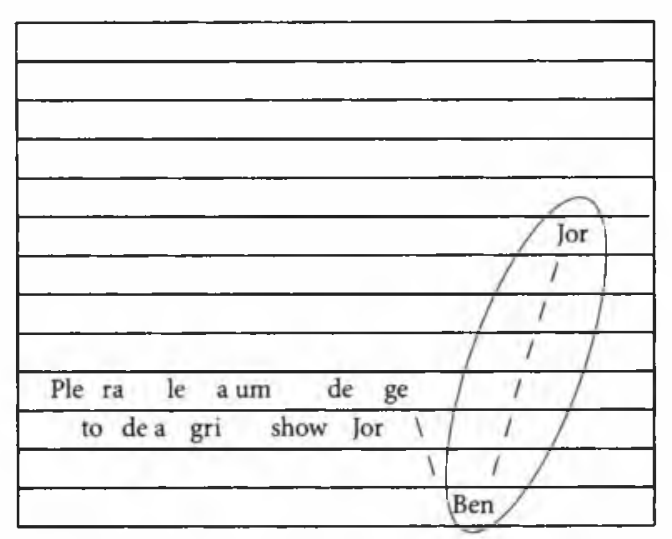

$6^{\mathrm{a}}$ seqüência da $2^{\mathrm{a}}$ estrofe

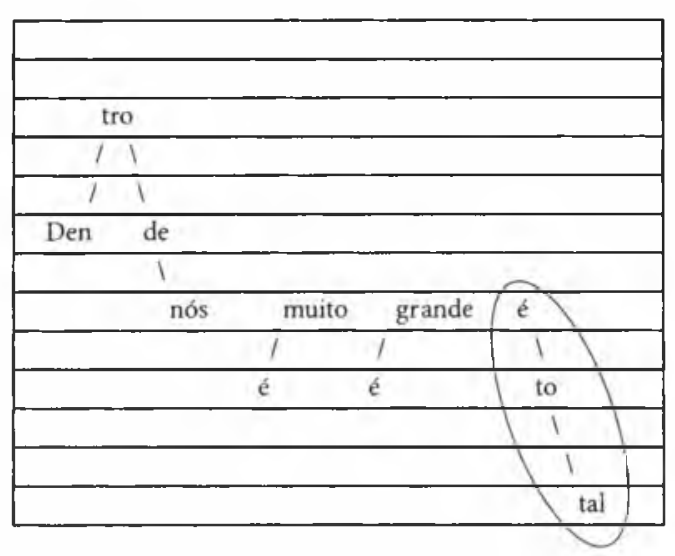

Geralmente as composições prevêem uma configuração melódica estável para garantir a unidade das estrofes em meio às variações de conteúdo criadas na letra. "Fora da Ordem" acena nessa direção, mas somente para valorizar os momentos em que a construção dos versos exige também alteração melódica. De fato, se a 
quinta seqüência da segunda estrofe perfaz, sem grandes alterações, o contorno da quinta seqüência da estrofe inicial, a seqüência seguinte (a sexta) introduz transformações tão radicais quanto significativas para a nossa descrição. Comparemos sua manifestação na primeira e na segunda estrofe:

$6^{a}$ seqüência da $1^{a}$ estrofe

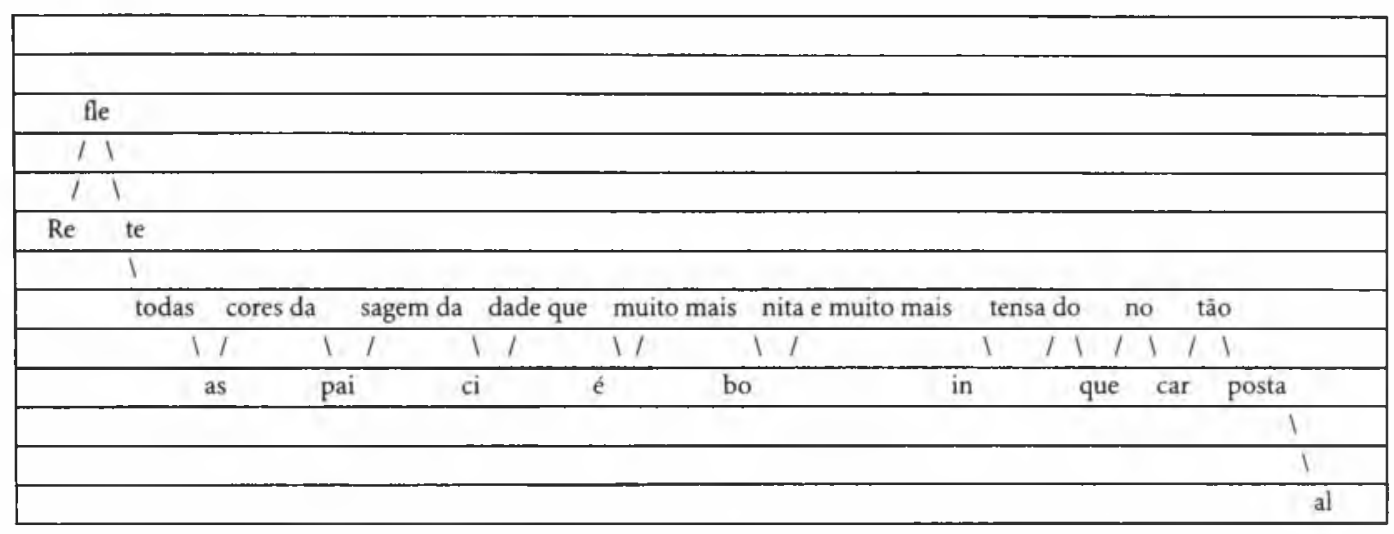

$6^{\mathrm{a}}$ seqüência da $2^{\mathrm{a}}$ estrofe

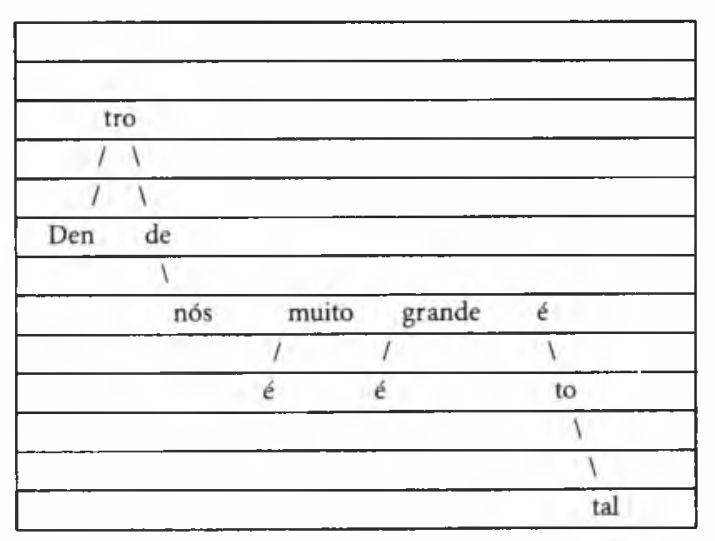

Esta última seqüência apresenta uma versão condensada do material melódico exuberante introduzido na anterior: apenas suas direções e seus intervalos essenciais. Arma-se, então, um esquema concessivo: embora esse trecho tenha sido criado para alojar os momentos de exorbitância entoativa (como ocorre nas primeira e terceira estrofes) da canção, durante a segunda estrofe, ele se adapta também a uma solução estritamente econômica da forma musical (aquela que não permite os arroubos do desdobramento silábico). Podemos imaginar assim que o esquema concessivo, tão empregado na composição dos versos, transfere-se para a me- 
lodia justamente na estrofe em que se afasta do domínio da letra. Ou seja, a melodia também quer dizer que não há exclusivamente atropelo e precipitação no universo cinemático e aspectual brasileiro. Na mesma zona de imbricação temporal pode haver distribuição pausada das células melódicas e respeito aos ciclos de duração (ver no diagrama: "é muito [pausa] é grande [pausa] é total”).

E se melodia e letra revezam-se no que tange ao uso da concessão, ambas mantêm o paralelismo na assunção dos valores fóricos - que compreendem aqui valores cinemáticos e aspectuais. A melodia manifesta sua versão econômica e bem dosada no tratamento dos motivos exatamente na estrofe em que a letra se concentra na expressão dos conteúdos eufóricos e atraentes da canção.

O inverso desse paralelismo pode ser apreciado por fim na sétima seqüência, quando a forma musical impõe recorrências à melodia para assegurar sua estabilidade como refrão enquanto a letra registra, nos termos já examinados, a condição out of order do mundo atual. A melodia encena a "ordem mundial" para que, desse contexto organizado, a letra revele os sujeitos excluídos, desde o enunciador principal (o cantor) - cuja presença na canção foi sobejamente enfatizada pelas embreagens na letra e pelas intervenções entoativas no plano melódico - até os representantes de outros povos que, no final, se revezam nessa função, conservando suas línguas de origem:

$7^{\mathrm{a}}$ seqüência

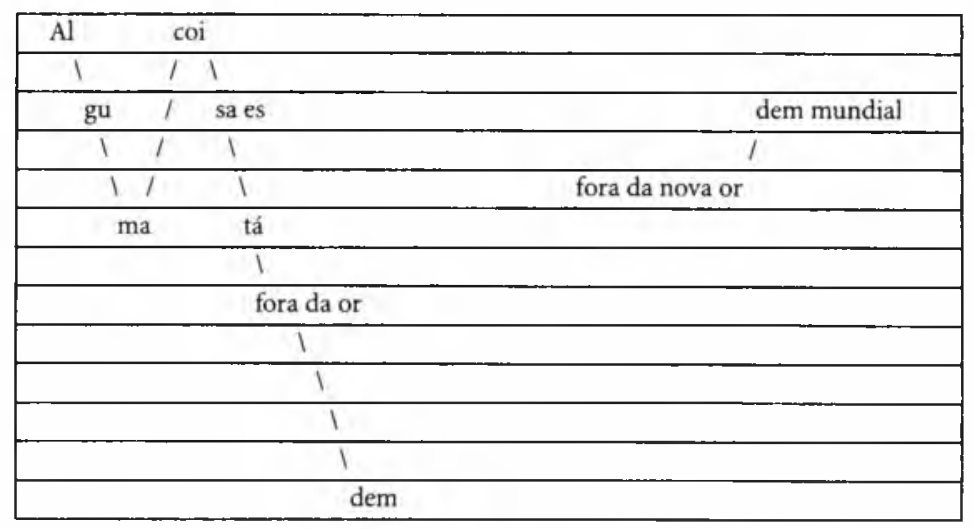

Para concluir O disco Circuladô, de que faz parte a canção aqui destacada, foi elaborado numa época em que Caetano se indagava, contra o pano de fundo da propalada "nova ordem mundial", sobre a viabilidade do Brasil como projeto. 
Segundo um depoimento seu à revista La Maga (Buenos Aires, 29 de abril de 1992), "Fora da ordem" pretende ser "o veículo de uma visão do Brasil, por um lado sombria demais, por outro, luminosa demais. Há uma dor e também uma alegria por estar, de algum modo, fora da nova ordem mundial". Nosso breve exame levounos a concluir que tal ambigüidade - verificável pelos parâmetros da aspectualidade, do andamento, da foria, da juntividade, da figuratividade, das relações métricas e melódicas - faz-se presente não somente na letra, mas na canção vista como o indissolúvel conjunto de letra e música. A manutenção dessa tensa complexidade, na medida em que possa ser vista como representativa, reforça aquela impressão emitida há tempos por Tom Jobim, que costumava dizer que "o Brasil não é para principiantes"

Desde que se respeitem as especificidades da linguagem de manifestação com que estejamos lidando, já é possível entrever hoje em dia algumas pistas para uma abordagem mais criteriosa dos dispositivos internos de produção do sentido na canção, não obstante o muito que ainda há por avançar na matéria. Como quer que seja, temos o sentimento de que isso pode representar um passo a mais na direção de uma semiótica integrada, atenta simultaneamente, de acordo com os votos de Hjelmslev, à descrição da expressão e do conteúdo.

Ivã Carlos Lopes e Luiz Tatit são professores do Departamento de Lingüística da FFLCH-USP. 